\title{
ROCHAS ORNAMENTAIS: ALTERABILIDADE DOS GNAISSES ENDERBÍTICOS NO ENSAIO DE LIXIVIAÇÃO CONTÍNUA ATRAVÉS DO EXTRATOR SOXHLET
}

\author{
Anna Paula Lima Costa \\ Instituto Federal de Educação, Ciência e Tecnologia do Rio Grande do Norte \\ e-mail: anna.costa@ifrn.edu.br \\ José de A. Nogueira Neto \\ Universidade Federal do Ceará - Departamento de Geologia \\ e-mail: nogueira@ufc.br. \\ Tamar Milca B. Galembeck \\ Universidade Estadual Paulista Júlio Mesquita - Departamento de Petrologia e \\ Metalogenia/IGCE/UNESP e-mail: tamarmbg@ @rc.unesp.br \\ Zenaide C. Gonçalves da Silva \\ Universidade Nova de Lisboa/Faculdade de Ciências e Tecnologia/CEGUNLP/CEGDCT \\ e-mail: zcs@fct.unl.pt \\ Joaquim A. Simão \\ Universidade Nova de Lisboa/Faculdade de Ciências e Tecnologia/CEGUNLP/CEGDCT \\ e-mail: jas@fct.unl.pt
}

\section{RESUMO}

Os materiais estudados foram denominados de Verde Netuno, Verde Santa Cruz e Verde Choró, respectivamente para os granulitos das regiões de Itapipoca, Granja e Chorozinho. Foram pesquisados quanto aos aspectos tecnológicos e alteração/alterabilidade quando em uso. O objetivo principal deste trabalho foi estudar as alterabilidades das rochas selecionadas e observar os seus comportamentos uma vez expostas à ação dos agentes de alteração em laboratório, em condições correlacionáveis às do ambiente em que poderão ser aplicadas. Os estudos de alterabilidade realizados em rochas granulíticas demonstraram que, mesmo rochas aparentemente pouco susceptíveis a alteração, podem apresentar problemas de degradação quando submetidas a ambientes poluídos quimicamente agressivos. Sobre estes aspectos, observou-se que as características petrográficas e os índices físicos (porosidade e absorção) são ferramentas muito importantes para a avaliação da durabilidade das rochas como materiais de revestimento. No contexto geral estas rochas mostraram-se bastante resistentes para uso como materiais de revestimentos.

PALAVRAS-CHAVE: Rochas Ornamentais, Alterabilidade, Gnaisses Enderbíticos.

\section{DIMENSION STONES: WEATHERABILITY OF ENDERBITIC GNEISSES INDUCED BY SOXHLET TEST}

\begin{abstract}
The denominations Green Netuno, Green Santa Cruz and Green Choró were given to the granulites of Itapipoca, Granja and Chorozinho, respectively. The research was carried out taking in account the technological aspects and weathering/weatherability when in use. The essential aim of this work is to study the alterability of selected rocks and to observe their behavior once exposed to alteration agents in a laboratory environment comparable to actual environments where these rocks are used. The alterability studies conducted in granulitic rocks demonstrated that, even rocks with an apparent
\end{abstract}


low susceptibility to alteration, may in fact problems when submitted to chemically aggressive polluted environments. On these aspects, it was possible to notice that both the petrographic characteristics and the physical parameters (porosity and absorption) are very important tools for the evaluation of the durability of the rocks as coating materials. Therefore, in a general context the rocks studied are quite resistant regarding both to the alteration capacity and to the technological characteristics.

KEY WORDS: Dimension Stones, Weathering, Enderbitic Gneisses

\section{ALTERABILIDADE DOS GNAISSES ENDERBÍTICOS NO ENSAIO DE LIXIVIAÇÃO CONTÍNUA ATRAVÉS DO EXTRATOR SOXHLET}

\section{INTRODUÇÃO}

Os materiais utilizados nesta pesquisa são três (3) litotipos de rochas metamórficas de alto grau (granulito), classificadas no diagrama QAP (STRECKEISEN, 1974) como rochas enderbíticas. Sua cor varia de verde a cinza escuro e apresentam granulação de fina a média, com estruturação marcada por minerais planares.

Essas rochas ainda não são exploradas comercialmente e se apresentam na forma de matacões e maciços. Recebem as denominações: Verde Netuno, Verde Santa Cruz e Verde Choró e são provenientes, respectivamente, das regiões de Itapipoca, Granja e Chorozinho. Os enderbitos foram selecionados dentre os litotipos metamórficos encontrados nas respectivas regiões por apresentarem características estéticas (cor) e quantitativas (volume) aceitas para utilização no setor de rochas ornamentais. Embora os parâmetros tecnológicos dos tipos rochosos possam diferir os limites aceitáveis e adequados a cada uso são comuns. Assim, um melhor desempenho na quantificação dos parâmetros tecnológicos se torna cada vez mais significativo.

O ensaio de lixiviação contínua através do extrator Soxhlet já vem sendo utilizado como modo de avaliação da alterabilidade das rochas silicatadas há bastante tempo, como pode ser visto em Simão (1996), Simão e Silva (1997), Filho e Rodrigues (1997), Antão (2001) e Simão (2003).

Para avaliar as mudanças ocorridas nos gnaisses enderbíticos Verde Netuno, Verde Santa Cruz e Verde Choró, quando submetidos às condições deste ensaio, foram analisadas as mudanças macroscópicas ocorridas, discutida a perda de peso das amostras, bem como, os resultados das análises químicas das águas dos ciclos de lixiviação, das rochas frescas e alteradas e do resíduo das soluções. Os resultados encontram-se, respectivamente, nas tabelas 1, 2, 3 e 4.

\section{O SETOR DE ROCHAS ORNAMENTAIS}

O mercado de rochas ornamentais e de revestimento compreende os mármores e granitos, que perfazem cerca de $90 \%$ da produção mundial, e outras rochas de revestimento, segundo as suas respectivas conceituações comerciais:

Mármores: rochas calcárias ou dolomíticas, sedimentares ou metamórficas, que possam receber desdobramento seguido de beneficiamento (polimento, apicoamento, etc.);

Granitos: grande variedade de rochas silicáticas de origem tanto ígnea quanto metamórfica, rocha não calcária ou dolomítica, que apresenta boas condições de desdobramento, seguida de 
beneficiamento (polimento, apicoamento ou flameamento);

Rochas para Revestimento: (definição da NBR 15012/03) rochas naturais que, submetidas a processos diversos e graus variados de desdobramento e beneficiamento, são utilizadas no acabamento de superfícies, especialmente em pisos e fachadas, em obras de construção civil. Essa definição pode ser considerada similar à que a American Society for Testing and Materials (ASTM, 2001) propõe para dimension stone: pedra natural que foi selecionada, regularizada ou cortada em tamanhos e formas especificados ou indicados, com ou sem uma ou mais superfícies mecanicamente acabadas. Ou seja, é toda rocha natural mais ou menos tratada/beneficiada (bruta, aparelhada, flamejada ou polida), utilizada no acabamento de superfície de obras civis.

Rochas Ornamentais: (definição da NBR 15012/03) material rochoso natural, submetido a diferentes graus e/ou tipos de beneficiamento ou afeiçoamento (bruta, aparelhada, picotada, esculpida ou polida) utilizado para exercer uma função estética.

\section{ANÁLISE DA ALTERABILIDADE}

Define-se alteração de uma rocha como sendo sua desintegração e decomposição levadas a cabo por agentes físicos e químicos naturais, que a transformam em outro produto natural, em equilíbrio físico-químico com o meio ambiente. Alterabilidade é a aptidão do material rochoso para se alterar em função do tempo (AIRES BARROS, 1991).

Outros processos de alterações naturais de minerais são os derivados do metamorfismo, os quais ocorrem pelas mudanças de temperatura e pressão do ambiente natural das rochas, tal quais os envolvidos na formação dos gnaisses enderbíticos estudados.

A alterabilidade de um material é a sua taxa de alteração em determinado tempo. Os ensaios de alterabilidade se preocupam com o que pode acontecer, especialmente sob influência antrópica direta ou indireta, após a aplicação dos materiais pétreos. É através de testes de alterabilidade que se tenta prever e/ou prevenirem a ocorrência de futuras patologias das rochas.

Geralmente, a facilidade de alteração está relacionada às condições de cristalização dos minerais. Aqueles que se cristalizaram a temperaturas mais elevadas, em geral, terão um intervalo de estabilidade menor e, portanto, serão mais facilmente alterados.

O grau de alterabilidade dos minerais é uma característica fundamental no estudo das rochas, principalmente para aproveitamento como rochas ornamentais.

\section{METODOLOGIA}

\section{Caracterização da área de estudo}

As ocorrências granulíticas em questão estão distribuídas no Estado do Ceará, da seguinte forma: na porção noroeste das cidades de Itapipoca e Granja, e a nordeste e sudoeste da cidade de Chorozinho. $\mathrm{O}$ acesso às áreas estudadas, partindo-se de Fortaleza, segue os seguintes trajetos:

Itapipoca - pela BR-222, passando-se por Caucaia, Croatá, São Luis do Curú até Umirim, de onde se segue para norte pela CE-016, por aproximadamente $30 \mathrm{Km}$, até a sede do município (125 km de Fortaleza). Daí, segue-se, por estrada de terra batida, por aproximadamente $15 \mathrm{Km}$ a noroeste de Itapipoca; 
Granja - pela BR-222 até Sobral, a partir de onde de segue pela CE-071, passando por Martinópoles até a sede do município de Granja $(322 \mathrm{~km})$, de onde a área em estudo dista aproximadamente $6 \mathrm{~km}$ a noroeste;

Chorozinho - via BR-116, passando por Itaitinga, Horizonte e Pacajús, percorrendo aproximadamente $64 \mathrm{~km}$. Dessa posição, segue-se por estrada de terra batida por mais ou menos 6 $\mathrm{km}$ a sudeste de Chorozinho.

\section{ENSAIO DE LIXIVIAÇÃO CONTÍNUA COM EXTRATOR SOXHLET}

O ensaio de lixiviação contínua é realizado com o extrator Soxhlet, que constitui um dispositivo utilizado em laboratório, com o objetivo de simular a lixiviação de rochas e dos minerais durante determinado período de tempo. O ambiente caracterizado corresponde a um clima hipertropical, ou seja, quente e úmido com chuvas abundantes na estação úmida e períodos secos com temperatura variando entre $20^{\circ} \mathrm{C}-25^{\circ} \mathrm{C}$ (AIRES BARROS, 1991).

A montagem do extrator Soxhlet é constituída essencialmente de um balão de destilação, uma coluna extratora, uma unidade de condensação e um sifão. O procedimento de ensaio está detalhadamente descrito em Aires Barros e Miranda (1979).

A metodologia aplicada neste ensaio seguiu os procedimentos utilizados por Simão (2003). O ensaio foi realizado no Laboratório de Rochas Ornamentais do Departamento de Ciências da Terra da Universidade Nova de Lisboa. O esquema de funcionamento do ensaio é simples e resume-se ao fato da água, inicialmente destilada, ser aquecida, evaporada e condensada, percolando pelos fragmentos da rocha, após precipitação.

São utilizados fragmentos irregulares de rocha com peso de $10 \mathrm{~g}$ a $30 \mathrm{~g}$ cada, com os quais foi preenchido o extrator, em um arranjo que permite, ao mesmo tempo, um gotejar e percolações fáceis. $\mathrm{O}$ equipamento é posto em funcionamento contínuo. $\mathrm{O}$ ensaio se inicia com a colocação de fragmentos da rocha de massa conhecida no dispositivo. Foram efetuados 10 ciclos de $500 \mathrm{~h}$, totalizando 5000 h, e após cada ciclo, a água de circulação foi retirada, filtrada e substituída por um novo volume de água deionizada.

Ao final das $5000 \mathrm{~h}$, os fragmentos rochosos foram novamente pesados, e suas massas comparadas com a massa inicial, caracterizando-se, portanto a perda de massa.

$\mathrm{Na}$ tentativa de melhor entender as mudanças ocorridas nos gnaisses enderbíticos da porção norte do Estado do Ceará, foram realizadas observações macroscópicas, análise química das águas dos ciclos de lixiviação, análises químicas das rochas frescas e alteradas e análise do resíduo das soluções.

\section{RESULTADOS E DISCUSSÕES}

\section{Observação macroscópica dos fragmentos de rochas e peso das amostras}

As observações aqui descritas foram realizadas antes e após a realização do ensaio de lixiviação (COSTA, 2007).

Como os gnaisses enderbíticos Verde Netuno, Verde Santa Cruz e Verde Choró exibem composição mineralógica semelhante, as alterações analisadas são análogas. Nos três materiais foi observada 
marcante mudança de cor, os fragmentos, inicialmente de cor grafite a esverdeada, passaram a exibir cor rosa-avermelhado (figura 1). Isso sugere tratar-se de óxido de ferro residual, provavelmente resultante da alteração da biotita, anfibólio e piroxênio.

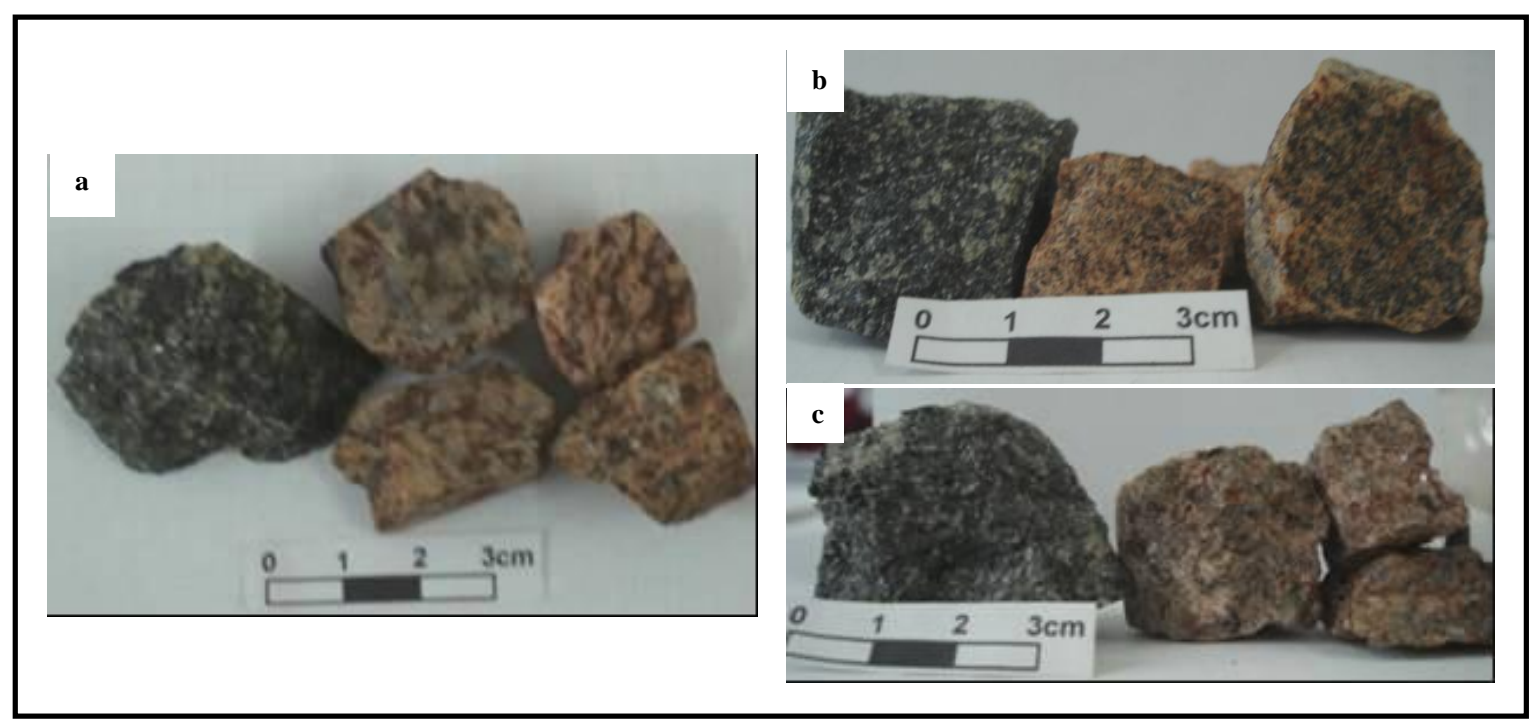

Figura 1: Aspecto macroscópico antes (material esverdeado) e após (material rosa) o ensaio de lixiviação contínua através do extrator Soxhlet dos gnaisses enderbíticos: a) Verde Netuno; b) Verde Santa Cruz; e c) Verde Choró

Os cristais de ortoclásio, tanto do Verde Netuno quanto do Verde Choró, apresentaram em sua superfície um pó fino de cor esbranquiçada, provavelmente caulinita.

Como citado anteriormente, os materiais, antes e após o ensaio, foram pesados, para se determinar sua perda de massa (tabela 1).

Tabela 1: Perda de massa total após o ensaio de lixiviação contínua através do extrator Soxhlet dos gnaisses enderbíticos da porção norte do Estado do Ceará

\begin{tabular}{l|c|c|r|r}
\hline \multirow{2}{*}{ Amostra } & \multicolumn{3}{|c|}{ Massa (g) } & \multirow{2}{*}{$\Delta \mathbf{M}(\%)$} \\
\cline { 2 - 4 } & Inicial & \multicolumn{1}{|c|}{ Final } & Perda de massa & \\
\hline Verde Netuno & 254,1461 & 250,8242 & 3,3219 & 1,3070 \\
\hline $\begin{array}{l}\text { Verde Santa } \\
\text { Cruz }\end{array}$ & 228,5905 & 227,6248 & 0,9657 & 0,4224 \\
\hline Verde Choró & 233,7487 & 232,0202 & 1,7285 & 0,7394 \\
\hline
\end{tabular}

$\Delta \mathrm{M}(\%)$ - Perda de massa

Novamente observa-se que a maior perda de peso ocorreu no Verde Netuno $(3,3219 \mathrm{~g})$ e a menor no Verde Santa Cruz $(0,9657 \mathrm{~g})$ (figura 2). Condizentes com os índices físicos e as características petrográficas descritas: porosidade $(0,23 \%$ e $0,55 \%)$; absorção de água $(0,20 \%$ e $0,09 \%)$; microfissuramento intergrão $(0,14 \%$ e $0,0 \%)$; e granulação (média e média-fina), respectivamente, para os Verde Netuno e Santa Cruz. 


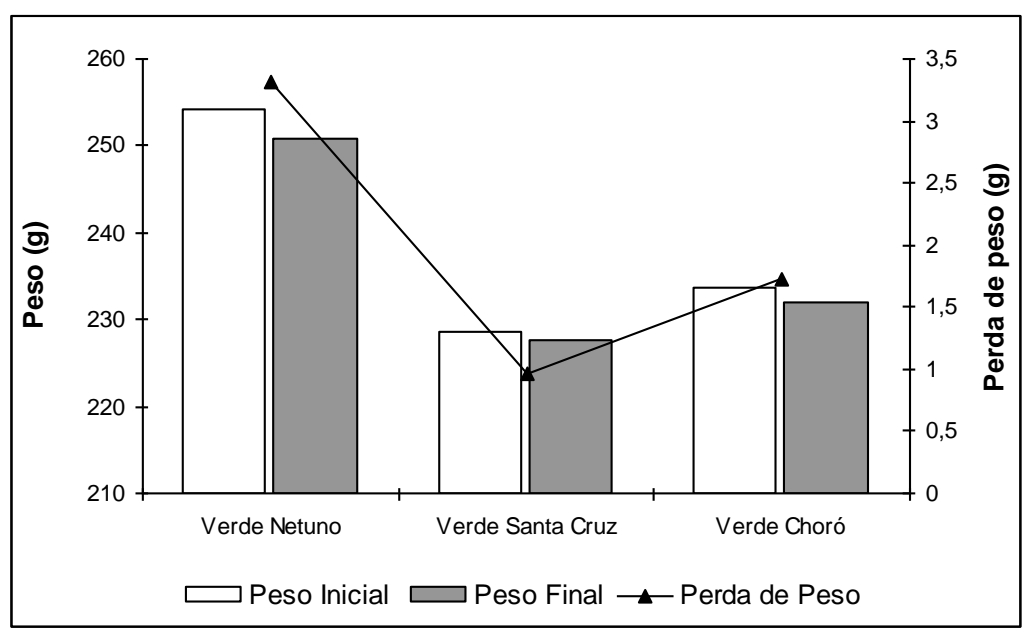

Figura 2: Peso inicial, peso final e perda de peso após o ensaio de lixiviação contínua através do extrator Soxhlet dos gnaisses enderbíticos da porção norte do Estado do Ceará

Podemos afirmar que quanto menores forem as alterações observadas, menor a perda de massa, maior será a qualidade da rocha, ou seja, apresentará um melhor comportamento quando exposta às condições do ensaio.

\section{ANÁLISE QUÍMICA DAS ÁGUAS DOS CICLOS DE LIXIVIAÇÃo}

No final de todos os ciclos de 500 horas, as águas de percolação foram recolhidas e submetidas à análise química de elementos maiores ( $\mathrm{Si}, \mathrm{Al}, \mathrm{Fe}, \mathrm{Mg}, \mathrm{Ca}, \mathrm{Na}, \mathrm{e} \mathrm{K}$ ), por absorção atômica. Essa técnica é aplicada para monitorar a degradação sofrida durante o processo de lixiviação dos cátions. Os resultados destas análises estão no apêndice A.

Na tabela 2 estão expressas as fases minerais que, em cada rocha, poderão ter sido dissolvidas e contribuir com a mobilidade de determinado elemento na solução analisada. Foram levadas em consideração as análises petrográficas e a análise química mineral.

Tabela 2: Minerais essenciais, dos gnaisses enderbíticos da porção norte do Estado do Ceará, que contribuíram para a presença de determinados elementos em solução

\begin{tabular}{|c|c|c|c|}
\hline Óxidos Amostra & Verde Netuno & Verde Santa Cruz & Verde Choró \\
\hline $\mathrm{SiO}_{2}$ & Todas as fases minerais & Todas as fases minerais & Todas as fases minerais \\
\hline $\mathrm{Al}_{2} \mathbf{O}_{3}$ & $\begin{array}{c}\text { albita, oligoclásio, } \\
\text { ortoclásio }\end{array}$ & oligoclásio, muscovita & $\begin{array}{c}\text { albita, oligoclásio, } \\
\text { ortoclásio }\end{array}$ \\
\hline $\mathbf{F e}_{\text {total }}$ & biotita e hornblenda & biotita e hornblenda & hornblenda e biotita \\
\hline MgO & piroxênio & piroxênio & piroxênio, biotita \\
\hline $\mathrm{CaO}$ & $\begin{array}{c}\text { hornblenda, } \\
\text { clinopiroxênio, albita e } \\
\text { oligoclásio }\end{array}$ & hornblenda, oligoclásio, & $\begin{array}{c}\text { hornblenda, } \\
\text { clinopiroxênio, } \\
\text { oligoclásio }\end{array}$ \\
\hline $\mathrm{Na}_{2} \mathrm{O}$ & $\begin{array}{c}\text { albita, oligoclásio e } \\
\text { andesina }\end{array}$ & oligoclásio e andesina & oligoclásio e andesina \\
\hline $\mathbf{K}_{2} \mathbf{O}$ & ortoclásio, biotita & plagioclásio, biotita & ortoclásio, biotita \\
\hline
\end{tabular}


Quando analisada a quantidade relativa dos elementos nas soluções de percolação (apêndice A), verificou-se que o silício $\left(\mathrm{Si}_{(40,68-104,17)}\right)$, o sódio $\left(\mathrm{Na}_{(3,58-13,85)}\right)$, o cálcio $\left(\mathrm{Ca}_{(2,30-5,47)}\right)$ e o potássio $\left(\mathrm{K}_{(0,42-14,16)}\right)$ são os elementos mais mobilizados pela lixiviação de vários minerais, principalmente os plagioclásios, que são o mais abundantes nos gnaisses enderbíticos analisados.

No Verde Netuno, os elementos mais detectados em solução, em ordem quantitativa decrescente, foram $\mathrm{Si}, \mathrm{Na}, \mathrm{K}$ e Ca. No Verde Santa Cruz, foram $\mathrm{Si}, \mathrm{Na}, \mathrm{Ca}, \mathrm{K}$ e Al e no Verde Choró foram Si, $\mathrm{Na}, \mathrm{K}, \mathrm{Al}$ e Ca. Vale destacar que o Verde Santa Cruz foi o que apresentou menor mobilidade quantitativa de seus elementos, corroborando positivamente com os dados de perda de massa.

\section{ANÁLISE QUÍMICA DAS ROCHAS FRESCAS E DAS ALTERADAS (APÓS ENSAIO)}

A partir da comparação entre a composição química da rocha antes e após o ensaio de lixiviação, é possível verificar quais elementos permaneceram constantes na rocha durante a alteração.

$\mathrm{Na}$ tabela 3 são apresentadas as composições químicas das rochas antes e após o ensaio de lixiviação continua com Soxhlet.

Observa-se que, assim como citado anteriormente, ocorreram mobilidades para as soluções, mas que após o ensaio nem sempre o comportamento dos elementos na composição na rocha total seguiu os padrões esperados em situações de alteração, como já demonstrado por Simão, 2003.

Tabela 3: Análise química de rocha total em amostras dos gnaisses enderbíticos da porção norte do Estado do Ceará, antes e após o ensaio de Soxhlet

\begin{tabular}{lrrrrr|r|r}
\hline Amostras & $\begin{array}{c}\text { Verde } \\
\text { Netuno } \\
\text { (Antes) }\end{array}$ & $\begin{array}{c}\text { Verde } \\
\text { Netuno } \\
\text { (Após) }\end{array}$ & $\begin{array}{c}\text { Verde Santa } \\
\text { Cruz } \\
\text { (Antes) }\end{array}$ & $\begin{array}{c}\text { Verde Santa } \\
\text { Cruz } \\
\text { (Após) }\end{array}$ & $\begin{array}{c}\text { Verde Choró } \\
\text { (Antes) }\end{array}$ & $\begin{array}{c}\text { Verde Choró } \\
\text { (Após) }\end{array}$ \\
\hline $\mathrm{SiO}_{2}$ & 62,35 & 63,14 & 71,40 & 71,03 & 65,58 & 63,73 \\
$\mathrm{TiO}_{2}$ & 1,57 & 1,41 & 0,34 & 0,36 & 0,47 & 0,53 \\
$\mathrm{Al}_{2} \mathrm{O}_{3}$ & 14,77 & 14,41 & 14,76 & 14,46 & 15,12 & 15,51 \\
$\mathrm{Fe}_{2} \mathrm{O}_{3}$ & 7,13 & 7,47 & 3,16 & 3,67 & 5,05 & 5,53 \\
$\mathrm{MnO}$ & 0,07 & 0,10 & 0,04 & 0,05 & 0,07 & 0,06 \\
$\mathrm{MgO}$ & 1,75 & 1,52 & 0,95 & 1,06 & 2,97 & 3,48 \\
$\mathrm{CaO}$ & 4,84 & 4,36 & 3,18 & 3,23 & 4,98 & 5,24 \\
$\mathrm{Na}$ & 3,54 & 3,40 & 4,70 & 4,57 & 3,81 & 3,86 \\
$\mathrm{~K}_{2} \mathrm{O}$ & 3,38 & 3,65 & 1,24 & 1,25 & 1,33 & 1,39 \\
$\mathrm{P}_{2} \mathrm{O}_{5}$ & 0,54 & 0,51 & 0,08 & 0,08 & 0,18 & 0,20 \\
$\mathrm{LOI}$ & 0,07 & 0,06 & 0,17 & 0,25 & 0,44 & 0,46 \\
$\mathbf{S o m a}$ & $\mathbf{1 0 0 , 0 1}$ & $\mathbf{1 0 0 , 0 3}$ & $\mathbf{1 0 0 , 0 2}$ & $\mathbf{1 0 0 , 0 2}$ & $\mathbf{1 0 0 , 0 1}$ & $\mathbf{9 9 , 9 9}$
\end{tabular}

No Verde Netuno, o silício aumentou a sua concentração relativa e foi o elemento que apresentou maior quantidade nas soluções analisadas nos três gnaisses.

O mesmo ocorreu com o alumínio no Verde Choró, que, apesar de apresentar a maior quantidade nas soluções analisadas, teve um ganho na concentração relativa na rocha após o ensaio.

Para o ferro, ocorreu um aumento da concentração na rocha no final do ensaio, provavelmente devido à lixiviação das biotitas e das hornblendas, com sua posterior impregnação nos feldspatos. Nas soluções, foram determinadas apenas concentrações muito baixas de ferro. 
O magnésio e o cálcio tiveram comportamentos semelhantes nos três gnaisses. No Verde Netuno, foram retirados preferencialmente nos piroxênios. Nos Verdes Santa Cruz e Choró ocorreu o inverso. $\mathrm{O}$ fato do o $\mathrm{Ca}$ e o $\mathrm{Mg}$ terem aumentado a sua concentração relativa na rocha pode ser devido a uma maior lixiviação de outros elementos existentes na sua composição.

A perda relativa de sódio está relacionada à grande mobilidade que o mesmo tem em processos de alteração, no entanto, no Verde Choró a sua concentração aumentou.

No caso do potássio, a concentração relativa aumentou em todas as rochas, a pesar de ter sido o terceiro elemento mais abundante nas soluções analisadas.

Verificam-se cada vez mais que a complexidade dos fenômenos que envolvem as alterações não são simples de serem determinados, principalmente ao se observar o comportamento dos elementos essenciais presentes nas rochas antes e após o ensaio de lixiviação contínua por Soxhlet.

\section{ANÁLISE DO RESÍDUO SÓLIDO DAS SOLUÇÕES}

Com o intuito de se identificarem as fases minerais originais constituintes das rochas, foram realizadas as análises do resíduo sólido existentes em suspensão e no fundo do balão receptor ao final de cada ciclo de 500 horas. A ocorrência desses resíduos se deve ao fato de que, durante cada ciclo, são desagregadas e transportadas pequenas partículas de cada mineral nas descargas do extrator.

A partir dos difratogramas, resultante das análises dos resíduos sólidos dos gnaisses enderbíticos durante os 10 ciclos de 500h, os minerais identificados no resíduo sólido das filtragens dos ciclos do ensaio de Soxhlet estão resumidos na tabela 4.

Tabela 4: Minerais identificados nos resíduos sólidos das filtragens dos ciclos do ensaio de Soxhlet dos gnaisses enderbíticos da porção norte do Estado do Ceará

\begin{tabular}{l|l}
\hline \multicolumn{1}{c|}{ Amostras } & \multicolumn{1}{c}{ Minerais } \\
\hline Verde Netuno & $\begin{array}{l}\text { Biotita, hornblenda, plagioclásio, quartzo, talco, carbonato, apatita, hematita, } \\
\text { vermiculita, siderita, barita }\end{array}$ \\
\hline Verde Santa Cruz & $\begin{array}{l}\text { Biotita, hornblenda, plagioclásio, quartzo, talco, carbonato, clorita, apatita, moscovita, } \\
\text { barita }\end{array}$ \\
\hline Verde Choró & $\begin{array}{l}\text { Biotita, hornblenda, plagioclásio, quartzo, talco, carbonato, clorita, apatita, hematita, } \\
\text { siderita, moscovita, barita }\end{array}$ \\
\hline
\end{tabular}

Nos gnaisses enderbíticos, verifica-se que são similares nos minerais identificados e que são poucos os neoformados.

As formações do talco e do carbonato podem estar relacionadas com o aumento da quantidade do magnésio e cálcio na rocha total após o ensaio, como discutido no item anterior.

O surgimento da hematita e da siderita se deve à lixiviação dos óxidos de ferro e de cálcio formados a partir das alterações da biotita e do anfibólio/pirôxenio.

A formação de moscovita, vermiculita e clorita podem ser devida à elevada concentração de Si, $\mathrm{K}$ e Al, presente tanto nas soluções como na rocha total analisada, que surgiram após 1500 horas de ensaios, como resultando da alteração dos minerais constituintes das rochas. 
No geral os minerais observados não demonstram que os gnaisses enderbíticos apresentem algum grau de alteração elevado que possa restringir sua aplicação.

\section{CONSIDERAÇÕES FINAIS}

Nos estudos de alteração e alterabilidade dos gnaisses enderbíticos, foi possível avaliar, comparar e prever o comportamento dessas rochas quando expostas às variadas condições de diversos ambientes agressivos onde poderão ser aplicadas.

Os resultados mostraram que os ganisses enderbíticos são susceptíveis à deterioração em formas e intensidades variáveis, em conformidade com suas propriedades intrínsecas e com a situação simulada.

Nos ensaios de degradação artificial ou alteração acelerada, tanto de ciclo contínuo como de ciclo não contínuo, os gnaisses enderbíticos sofreram alterações como mudança de cor e perda de massa, praticamente insignificante.

O Verde Netuno, dentre os três ganisses, foi o que apresentou maior perda de massa, seguido pelo Verde Choró e pelo Verde Santa Cruz. Isso é corroborado pelos dados dos índices físicos e petrográficos descritos: porosidade $(0,55 \% ; 0,23 \%$ e $0,14 \%)$; absorção de água $(0,20 \% ; 0,09 \%$ e $0,05 \%)$; microfissuramento intergrão $(0,14 ; 0,0$ e 0,07$)$; e granulação (média a média-fina), respectivamente para os Verde Netuno, Santa Cruz e Choró.

Na lixiviação contínua através do extrator Soxhlet, nos três materiais foi observado que os fragmentos, inicialmente de cor grafite a esverdeada, passaram a exibir cor rosa-avermelhado, sugerindo tratar-se de óxido de ferro residual. Provavelmente resultante da alteração da biotita, do anfibólio e do piroxênio.

Quando analisada a quantidade relativa dos elementos nas soluções de percolação do extrator Soxhlet, verificou-se que o silício $\left(\mathrm{Si}_{(40,68-104,17)}\right)$, o sódio $\left(\mathrm{Na}_{(3,58-13,85)}\right)$, o cálcio $\left(\mathrm{Ca}_{(2,30-5,47)}\right)$ e o potássio $\left(\mathrm{K}_{(0,42-14,16)}\right)$ são os elementos mais mobilizados pela lixiviação de vários minerais, principalmente os plagioclásios, que são os mais abundante nos gnaisses enderbíticos analisados.

Nas análises dos resíduos sólidos das soluções do extrator Soxhlet, os gnaisses enderbíticos apresentam similaridade nos minerais identificados. São poucos os minerais neoformados. A moscovita, a vermiculita e a clorita surgiram após 1500 horas de ensaios, resultando da alteração dos minerais constituintes das rochas.

Verifica-se cada vez mais a complexidade dos fenômenos que envolvem as alterações não são simples de serem determinados, mas, no geral, as observações feitas não demonstram que os gnaisses enderbíticos apresentem algum grau de alteração elevado que possa restringir sua aplicação como rocha ornamental ou de revestimento.

É possível concluir que os ensaios e as análises propostos e realizados forneceram importantes indicações sobre o comportamento e as possíveis aplicabilidades dos gnaisses enderbíticos. Além de apontarem para o fato de que devem ser observadas as medidas de conservação dessas rochas.

Com a afirmação de que os gnaisses enderbítico são aptos a serem utilizados como rochas ornamentais e de revestimento e que, portanto, devem ser feitas pesquisas e planejamento para sua extração. 


\section{REFERÊNCIAS}

1. AIRES BARROS, L. Alteração e Alterabilidade de Rochas. Instituto Nacional de Investigação Científico - Centro de Petrologia e Geoquímica da Universidade Técnica de Lisboa - Portugal, n.1, p. 13-15, 1991.

2. ANTÃO, A. M. Some Aspects of chemical weathering of granites from Guarda (Portugal) induced by Soxhlet test. SWAPNET, Stone Weathering and Almospheric Pollution NETwork. 2001.

3. Associação Brasileira de Normas Técnicas - ABNT 2003 (NBR 15012). Rochas para revestimento de edificações, terminologia. Rio de Janeiro.

4. COSTA, A.P.L. Alterabilidade e caracterização tecnológica dos gnaisses enderbíticos da porção norte do estado do ceará com aplicação no setor de rochas ornamentais, 2007. Tese de doutoramento no curso de Pós-graduação da Universidade Estadual Paulista - Rio Claro/SP. 199p. 2007.

5. FILHO, C. C.; RODRIGUES, E. P. Indicadores de alterabilidade para rochas silicatada e carbonáticas em revestimentos. Rochas e Equipamentos, n. 48, 4º trimestre, p.70-92. 1997.

6. SIMÃO, J. A. dos R. S. Alteração e alterabilidade do arnortosíto de Angola utilizado como rocha ornamental. Trabalho de síntese apresentado no âmbito das provas APCC, Faculdade de Ciências e Tecnologia, Universidade Nova de Lisboa. 1996.

7. SIMÃO, J. A. dos R. S. Rochas Ígneas como Pedra Ornamental - Causas, Condicionantes e Mecanismos de Alteração. Implicações Tecnológicas 2003. Tese de Doutoramento. Universidade Nova de Lisboa. FCT. Lisboa, 182p, 2003.

8. SIMÃO, J. A. dos R. S.; SILVA, Z. Anorthosito and ist use as dimension stone. Alterations as response to weathering in polluted environment. Internacional Symposium Engineering Geolgy and the Environmente, Atenas, Vol. III, p.3257-3262. 1997.

9. STRECKEISEN, A. How should charnockitic rocks be named. Centtenaire de la Société Géologique de Belqgique Géologie des domaines cristallins, Liège. p. 349-360. 1974. 